\title{
INFLUENCIA DE SUBSTRATOS NA FORMAÇÃO DOS PORTA-ENXERTOS: LIMOEIRO-CRAVO (Citrus limonia Osbeck) E TANGERINEIRA-CLEÓPATRA (Citrus reshni Hort. Ex Tanaka) EM AMBIENTE PROTEGIDO ${ }^{1}$
}

\author{
MARCOS ANTÔNIO JABUR² \& ANTONIO BALDO GERALDO MARTINS ${ }^{3}$
}

\begin{abstract}
RESUMO - Visando a estudar o efeito do substrato na produção de porta-enxertos de limoeiro-Cravo e tangerineira-Cleópatra em tubetes sob ambiente protegido, conduziu-se este trabalho na Faculdade de Ciências Agrárias e Veterinárias de Jaboticabal-UNESP. O estudo foi realizado em ambiente coberto com sombrite preto sem proteção lateral, adotando-se delineamento inteiramente casualizado, em esquema fatorial 5x2, 4 repetições e 20 sementes por parcela. Utilizaram-se os substratos húmus de minhoca oriundo de esterco de curral $\left(\mathrm{H}_{\sigma_{6}}\right)$ e vermiculita média $\left(\mathrm{V}_{\sigma_{6}}\right)$, sendo $\mathrm{S} 1=\mathrm{H}_{0} \mathrm{~V}_{100} ; \mathrm{S} 2=\mathrm{H}_{25} \mathrm{~V}_{75} ; \mathrm{S} 3=\mathrm{H}_{50} \mathrm{~V}_{50} ; \mathrm{S} 4=\mathrm{H}_{75} \mathrm{~V}_{25}$ e $\mathrm{S} 5=\mathrm{H}_{100} \mathrm{~V}_{0}$. Avaliaram-se o número de plântulas emergidas, altura das plantas, diâmetro do caule, massas fresca e seca de raiz e parte aérea. Observaram-se resultados estatisticamente significativos para diâmetro do caule, aos 104 e 118 dias após a semeadura (DAS) entre espécies, com superioridade de Cravo em relação a Cleópatra, porém não aos 132 DAS. Não foi constatada diferença significativa entre os substratos. Quanto à massa fresca de parte aérea, nenhuma diferença estatística ocorreu entre as espécies; porém, quanto aos substratos, S3 mostrou-se superior a S1, não diferindo, entretanto, dos demais. Embora a análise estatística não tenha mostrado diferenças significativas entre os tratamentos para os outros parâmetros analisados, S3 destacou-se entre os substratos testados.
\end{abstract}

Termos para indexação: citros, húmus, vermiculita.

\section{INFLUENCE OF THE SUBSTRATE FOR OBTENTION TO RANGPUR LIME (Citrus limonia Osbeck) AND CLEOPATRA MANDARIN (Citrus reshni Hort. Ex Tanaka) ROOTSTOCK IN GREENHOUSE}

\begin{abstract}
The objetive was study the effect of the substrate for obtention to rangpur lime and Cleopatra madarin rootstock in greenhouse. The experiment was carried out in the Faculdade de Ciências Agrárias e Veterinárias de Jaboticabal-UNESP. The study was realized in greenhouse cover whit black "sombrite" without lateral protection, employing the DIC in $5 \times 2$ factorial scheme, 4 replications and 20 seeds per plot. The substrates humus and vermiculite were compared $\left(\mathrm{S} 1=\mathrm{H}_{0} \mathrm{~V}_{100} ; \mathrm{S} 2=\mathrm{H}_{25} \mathrm{~V}_{75} ; \mathrm{S} 3=\mathrm{H}_{50} \mathrm{~V}_{50} ; \mathrm{S} 4=\mathrm{H}_{75}\right.$ $\mathrm{V}_{25}$ e S5= $\mathrm{H}_{100} \mathrm{~V}_{0}$ ). The number of emerged seedlings, plant length, stock diameter, fresh and dry matter of the root and aerial part were evaluated. Statistically significant results were observed for the following parameters: stock diameter at 104 and 118 DAS (Days After Planting) between species, whith superiority of the rangpur lime, but not in 132 DAS. Between treatment none statistically significant result were observed. For fresh and dry matter of the aerial part, none statistically significant results were observed between the species, but the treatment S3 was higher than the S1, not having differed statistically of the others. To the others parameters evaluated, although no statistically significant results were observed, the $\mathrm{S} 3$ can be detached.
\end{abstract}

Index terms: citrus, humus, vermiculite.

\section{INTRODUÇÃO}

A citricultura paulista, responsável por divisas da ordem de US $\$ 1,5$ bilhão/ano, ocupa área de aproximadamente 840 mil hectares de 340 municípios, sendo a principal zona exportadora de suco de laranja concentrado do mundo (ESCOBAR et al., 1999).

Contudo, doenças como o Cancro-Cítrico (Xanthomonas axonopodis pv. citri) e a Clorose Variegada dos Citros (Xylella fastidiosa), além do Declínio dos Citros (agente causal desconhecido), gomose (Phytophtora $s p$ ) e nematóides, que atingem as mudas, podem alterar este panorama.

Levantamento efetuado pelo Fundo Paulista de Defesa da Citricultura (FUNDECITRUS), em janeiro de 2001, mostrou que, das 19,324 milhões de mudas produzidas na região citrícola paulista, apenas 162 viveiros telados produziam 3,139 milhões.

Visando a solucionar em parte esses problemas, buscase, atualmente, a formação de mudas em ambientes protegidos, utilizando sementes oriundas de plantas sadias e borbulhas de origem conhecida.

A escolha do substrato é de fundamental importância, pois é onde o sistema radicular irá desenvolver-se, determinando o crescimento da parte aérea em tubete, até o momento do transplantio. Este substrato deve ser isento de patógenos, possuir bom equilíbrio entre macro e microporos para um bom desenvolvimento radicular, boa capacidade de retenção de água, boa consistência visando à obtenção de torrões intactos quando retirados do recipiente, baixo custo e fácil obtenção.

1 (Trabalho 060/2001). Recebido: 27/03/2001. Aceito para publicação: 02/05/2002.

2 M. S. Marcos Antônio Jabur - Prof. do Colégio Técnico Agrícola "José Bonifácio" - UNESP/Jaboticabal - Via de Acesso Prof. Paulo Donato Castellane, km 05 - maranjab@cta.unesp.br

3 Dr. Antonio Baldo Geraldo Martins - Prof. da Faculdade de Ciências Agrárias e Veterinária da UNESP/Jaboticabal - Via de Acesso Prof. Paulo Donato Castellane, km 05. 
Este trabalho tem por objetivo estudar os efeitos de diferentes misturas de substratos (húmus de minhoca oriundo de esterco de curral e vermiculita média) em ambiente protegido (telado), na produção de porta-enxertos de citros (tangerineiraCleópatra e limoeiro-Cravo), com a adição de adubo de liberação gradual de nutrientes Osmocote ${ }^{\circledR}$, como contribuição à adequada formação de mudas de qualidade.

\section{MATERIAL E MÉTODOS}

O experimento foi instalado na Faculdade de Ciências Agrárias e Veterinárias de Jaboticabal - UNESP, em 1999, em ambiente coberto com tela (sombrite de cor preta) sem proteção lateral, para formação de porta-enxertos de citros, distante mais de 200 metros do pomar de citros mais próximo.

As sementes de tangerineira-Cleópatra (CL) e de limoeiro-Cravo (CR) foram obtidas, respectivamente, de frutos colhidos na FCAVJ-UNESP e Estação Experimental de Citricultura de Bebedouro, sendo retiradas de plantas reconhecidamente sadias, lavadas sob água corrente e secas à sombra em local ventilado, em abril e maio de 1999 e classificadas por peneiras redondas. Obteve-se o número suficiente para a instalação do ensaio com as retidas pelas peneiras 13 (CR) e 15 (CL). Após, efetuouse o tratamento com Vitavax-Thiram 200 SC, $250 \mathrm{~mL} / 100 \mathrm{~kg}$ de sementes e armazenamento em câmara fria até a instalação do experimento, que se deu em 24 de setembro de 1999, que, segundo CARLOS et al. (1997), não acarreta perda do poder de germinação.

A semeadura foi efetuada em recipientes de plástico (tubetes) cônicos, com capacidade para $50 \mathrm{~cm}^{3}, 12,1 \mathrm{~cm}$ de altura e 6 estrias longitudinais internas, a 1,5 cm da borda, coberta com a mesma mistura de cada substrato e colocados em bandejas a 1 $\mathrm{m}$ do solo, sobre bancadas de madeira. Irrigou-se, manualmente, até o escorrimento de água pelo orifício inferior do recipiente, diariamente, durante todo o experimento.

O material húmico utilizado foi esterco de curral oriundo de minhocultura e, como material inerte, vermiculita média, encontrada no comércio.

O delineamento experimental adotado foi o inteiramente casualizado, em esquema fatorial $5 \times 2$, com 4 repetições e 20 plantas por parcela, constituindo área útil os 6 tubetes centrais. Pelas dimensões do ensaio, o ambiente protegido pode ser considerado uniforme, sendo estudados os seguintes tratamentos: 5 substratos (em \% de húmus e vermiculita, respectivamente): $\mathrm{S} 1=0$ e $100 ; \mathrm{S} 2=25$ e $75 ; \mathrm{S} 3=50$ e $50 ; \mathrm{S} 4=75$ e $25 ; \mathrm{S} 5=100$ e $0 ;$ e 2 porta-enxertos $(\mathrm{CL}=$ tangerineira-Cleópatra e $\mathrm{CR}=$ limoeiro-Cravo).

No preparo dos substratos, foi adicionado adubo de liberação gradual Osmocote ${ }^{\circledR}$ (mini-prill), fórmula e quantidade mínima indicadas pelo fabricante (19-06-10 (liberação de 3 a 4 meses), à base de $3 \mathrm{~kg} / \mathrm{m}^{3}$ de substrato). Foi observado diariamente o ensaio, visando a determinar-se o início da germinação, o que se deu aos 30 dias após a semeadura (DAS). Após serem computadas, as plântulas e seus respectivos tubetes, se porventura estivessem na bordadura, eram trocados com os centrais, visando a obter-se as 6 plantas da área útil de cada parcela.

A altura das plantas foi obtida através de medições da região do colo até a folha mais alta, com régua graduada em milímetros, semanalmente. Iniciou-se aos 80 DAS, quando se obteve o número mínimo de plantas da área útil da última parcela (tratamento S2-CL, aos 76 DAS), e terminando aos 132 DAS), quando as plantas atingiram estabilidade quanto ao parâmetro.

O diâmetro do caule de cada parcela foi determinado a cada duas semanas, iniciando-se aos 104 DAS e findando aos 132 DAS, utilizando-se de um paquímetro.

As massas fresca e seca de raiz e da parte aérea foram obtidas aos 134 e 139 DAS, respectivamente, pela pesagem em balança de precisão. A raiz e a parte aérea foram separadas com corte na região do colo. As raízes foram lavadas em água corrente para a eliminação dos substratos e secas com papel absorvente e as partes aéreas pesadas diretamente. Estes mesmos materiais foram posteriormente utilizados para a obtenção das massas secas respectivas, sendo levados a estufa de circulação forçada de ar a $65-70{ }^{\circ} \mathrm{C}$ até atingirem peso constante.

Os valores de temperatura foram obtidos em termômetros de máxima e mínima previamente calibrados.

\section{RESULTADOS E DISCUSSÃO}

As emergências de plântulas, bem como as médias das temperaturas máximas, encontram-se na Figura 3, onde se pode observar que tais valores estão de acordo com os descritos por vários autores como ótimos para a germinação, ou seja, 25 a $35^{\circ} \mathrm{C}$ por RADHAMANI et al. (1991) ou 30 a $35^{\circ} \mathrm{C}$ por DAVIES \& ALBRIGO (1994). As mínimas foram sempre superiores a $14^{\circ} \mathrm{C}$, não interferindo, portanto, na germinação (RADHAMANI et al., 1991).

Os dados de germinação para tangerineira-Cleópatra (CL) e limoeiro-Cravo (CR) encontram-se, respectivamente, nas Figuras 1 e 2, que demonstram os valores médios das plantas das 4 repetições e as curvas de tendência determinadas pela análise de regressão. Observa-se que, para CL, o máximo de germinação (10 plantas (50\%)) ocorreu aos 80 dias após a semeadura (DAS) no melhor tratamento (S1), seguido de S3 $(7,75(38,75 \%)$ aos 83 DAS), S5 (7,25 (36,25\%) aos 73 DAS), S4 (6,25 (31,25\%) aos 69 DAS) e S2 (6,00 (30\%) aos 76 DAS). Para CR, S1 mostrou o máximo de germinação aos 66 DAS $(14,25$ plantas $(71,25 \%)$ ), acompanhado de S2 (10,26 (51,30\%) aos 76 DAS), S3 e S4 (9,75 $(48,75 \%)$ aos 73 DAS) e S5 (7,75 (38,75\%) aos 69 DAS). Os valores encontrados estão de acordo com a literatura quanto à germinação, uma vez que, para todos os tratamentos, houve maior número médio de plântulas emergidas de CR em relação a CL (LIRA, 1990; CARVALHO, 1994). Pela análise dos resultados para ambas as espécies, o tratamento que proporcionou melhor germinação foi $\mathrm{S} 1$, ou seja, apenas vermiculita. Isto sugere que, quando da semeadura, devam-se colocar as sementes em contato apenas com este material.

Os valores de alturas de plantas encontram-se na Tabela 1 e nenhuma diferença significativa foi observada tanto para espécies quanto para substratos. A altura de $10 \mathrm{~cm}$, recomendada para repicagem, foi alcançada aos 111 DAS para CL e, como não houve diferença significativa entre os valores, o mesmo vale para CR. Quanto aos substratos, S3 destacou-se dos demais, embora não tenha diferido aos 125 e 132 DAS. A temperatura raramente ultrapassou os $36^{\circ} \mathrm{C}$ (Figura 3), quando a atividade vegetativa das plantas de citros diminui, nem tampouco atingiu 
$42^{\circ} \mathrm{C}$, a partir da qual se reduz a uma taxa mínima. O limite inferior foi sempre maior que $12,8^{\circ} \mathrm{C}$ (zero vegetativo), proporcionando condições ideais para o desenvolvimento das plantas (NOGUEIRA, 1979)

Os dados obtidos concordam com os de CARVALHO (1994) para altura até os 104 DAS para ambas as espécies, sendo o mesmo verificado para CL aos 118 DAS. Entretanto, para CR, nesta época, os valores descritos por aquele autor são maiores, devido, provavelmente, à capacidade dos recipientes de poliestireno expandido utilizados pelo mesmo $\left(75 \mathrm{~cm}^{3}\right)$ e do substrato "Plantmax" proporcionarem um maior desenvolvimento do sistema radicular, com conseqüente altura das plantas. Já JOAQUIM (1991), que trabalhou com recipientes de isopor e células de $35 \mathrm{~cm}^{3}$ de capacidade, mesmo aos 163 DAS, não obteve plantas, de ambas as espécies, aptas ao transplantio. O mesmo ocorreu com LIRA (1990) que, embora tenha utilizado recipientes de $80 \mathrm{~cm}^{3}$, porém terra e vermiculita como substrato, aos 135 DAS não obteve plantas próprias ao transplantio. Nenhuma diferença estatística foi observada entre substratos nem para a interação espécies x substratos para esse parâmetro.

Os valores encontrados para diâmetro de caule encontram-se na Tabela 2, onde, como era de se esperar, aos 104 e 118 DAS, CR mostrou-se com diâmetros maiores que CL, embora aos 132 DAS, nenhuma diferença estatística fora detectada. Este fato deve-se às características próprias de cada espécie, pois o primeiro é tido como um porta-enxerto vigoroso, de crescimento mais rápido que CL. Esta, por sua vez, caracteriza-se por apresentar crescimento em altura sem o correspondente engrossamento do caule, conforme foi demonstrado nas duas primeiras épocas de avaliação. Estes dados condizem com a literatura (CARVALHO, 1994; JOAQUIM, 1991). Não ocorreram diferenças entre substratos e interação $\mathrm{E}$ x $\mathrm{S}$.

Para massas fresca e seca de raiz e parte aérea, não foi encontrada diferença significativa entre espécies; porém, dentre os tratamentos, S3 mostrou-se superior a S1 (parte aérea), não diferindo, contudo, dos demais (Tabela 3). Embora todos os tratamentos que contivessem húmus em sua composição não tenham diferido estatisticamente entre si, os valores obtidos demonstram a importância de cada componente na mistura, quanto à aeração para o desenvolvimento radicular. Uma análise conjunta mais acurada dos dados obtidos, tanto para massa fresca quanto seca de raiz e de parte aérea, indicam destaque para S3, sugerindo que, para esses parâmetros, foi o melhor substrato. Os valores encontrados neste estudo estão aquém dos obtidos por CARVALHO (1994) e por LIRA (1990), porém, acima dos relatados por JOAQUIM (1991), provavelmente devido ao volume dos recipientes e composição dos substratos. Para CL, os valores concordam com os de CARVALHO (1994), porém não com os de JOAQUIM (1991) para massa seca de parte aérea, devido às características da espécie, que possui desenvolvimento mais lento que CR e o primeiro autor descreveu dos dados aos 120 DAS, ocasião em que o sistema radicular ainda estava em fase de expansão, havendo espaços no interior do recipiente a serem preenchidos pelo mesmo. O desenvolvimento da parte aérea em altura é determinado pelo comprimento do sistema radicular (simetria). JOAQUIM (1991), utilizando recipientes de 6 cm de altura, não obteve plantas superiores a 7,22 cm (CL) e 8,21 cm (CR) mesmo aos 163 DAS. A importância do substrato, além da altura do recipiente, ficou demonstrada no trabalho de LIRA (1990) que, apesar de utilizar recipientes de $12 \mathrm{~cm}$ e misturas de terra e vermiculita, além de "Plantmax" comercial, só obteve plantas com altura superior a $10 \mathrm{~cm}$ aos 135 DAS, tendo como média $8,5 \mathrm{~cm}$. O húmus de minhoca como componente de misturas para substrato é indicado por SEMPIONATO et al. (1997), que recomendam 3\% na mesma. Quanto à composição física do húmus e da vermiculita, ambos possuem alta porosidade, porém o primeiro apresenta apenas microporosidade elevada, enquanto a segunda mostra equilíbrio entre a macro e a microporosidades (GONÇALVES \& POGGIANI, 1996). Esta característica do húmus pode levar a uma redução na aeração e prejuízo para o desenvolvimento do sistema radicular. Isto deve ter ocorrido em S5 e S4. Pela predominância de vermiculita em S1 e S2, a aeração foi melhor, porém elevou a drenagem e não permitiu a formação de torrões com alta consistência, prejudicando a estrutura das raízes por ocasião do manuseio, o que não é recomendável. O equilíbrio desta característica (porosidade) foi conseguido em S3, motivo pelo qual se destacou nos parâmetros analisados neste estudo, embora não diferisse estatisticamente dos demais para altura de plantas, diâmetro de caules e massas fresca e seca de raízes.

Com relação à praticidade e à operacionalidade, recomenda-se a utilização de tubetes ao invés de bandejas de poliestireno expandido, pois a germinação das sementes das espécies estudadas não ocorre de maneira uniforme, e os recipi-

TABELA 1 - Alturas de plantas $(\mathrm{cm})$ de tangerineira-Cleópatra e de limoeiro-Cravo cultivados em diferentes substratos e avaliados aos $50 ; 57 ; 64 ; 73 ; 80 ; 84 ; 94 ; 104 ; 111 ; 118 ; 125$ e 132 dias após a semeadura (DAS).

\begin{tabular}{|c|c|c|c|c|c|c|c|c|c|c|c|c|}
\hline \multicolumn{13}{|c|}{ ALTURAS DE PLANTAS (cm) } \\
\hline ESPÉCIES/DIAS & 50 & 57 & 64 & 73 & 80 & 84 & 94 & 104 & 111 & 118 & 125 & 132 \\
\hline Tangerina-Cleópatra & $1,7260 \mathrm{a}$ & $2,4820 \mathrm{a}$ & $3,0215 \mathrm{a}$ & $4,8935 \mathrm{~b}$ & $5,5260 \mathrm{a}$ & $6,7250 \mathrm{a}$ & $7.6475 \mathrm{a}$ & $8,7140 \mathrm{a}$ & $10,1925 \mathrm{a}$ & $10,7220 \mathrm{a}$ & $11,4615 \mathrm{a}$ & $12,0270 \mathrm{a}$ \\
\hline Limão-Cravo & $2,2120 \mathrm{a}$ & $2,4960 \mathrm{a}$ & $3,4730 \mathrm{a}$ & $5,8325 \mathrm{a}$ & $6,0465 \mathrm{a}$ & $6,4290 \mathrm{a}$ & $8,2290 \mathrm{a}$ & $9,5835 \mathrm{a}$ & $9,7945 \mathrm{a}$ & $10,3560 \mathrm{a}$ & $11,3170 \mathrm{a}$ & $11,5830 \mathrm{a}$ \\
\hline Teste F & $2,6498 \mathrm{NS}$ & $0,0031 \mathrm{NS}$ & $2,2880 \mathrm{NS}$ & 8,8969 *** & $2,5465 \mathrm{NS}$ & $0,6762 \mathrm{NS}$ & $2,2995 \mathrm{NS}$ & $3,9244 \mathrm{NS}$ & $0,6200 \mathrm{NS}$ & $0,6998 \mathrm{NS}$ & $0,0901 \mathrm{NS}$ & $0,8735 \mathrm{NS}$ \\
\hline DMS (5\%) & 0,4846 & 0,5170 & 0,6100 & 0,9955 & 0,6665 & 0,7356 & 0,7836 & 0,8969 & 1,0330 & 0,8941 & 0,8941 & 0,9708 \\
\hline \multicolumn{13}{|l|}{ SUBSTRATOS } \\
\hline $\mathrm{S} 1-\mathrm{H}_{0} \quad \mathrm{~V}_{100}$ & $2.6513 \mathrm{a}$ & $3.0838 \mathrm{a}$ & $3.7215 \mathrm{a}$ & $5.6225 \mathrm{a}$ & $6.1138 \mathrm{a}$ & $6.7275 \mathrm{a}$ & $7.7738 \mathrm{a}$ & $9.2325 \mathrm{a}$ & $9.7200 \mathrm{a}$ & $10.0913 \mathrm{a}$ & $11.0288 \mathrm{a}$ & $11.1875 \mathrm{a}$ \\
\hline $\mathrm{S} 2-\mathrm{H}_{25} \quad \mathrm{~V}_{75}$ & $1.9825 \mathrm{ab}$ & $2.3225 \mathrm{a}$ & $2.9925 \mathrm{a}$ & $5.0850 \mathrm{a}$ & $5.4513 \mathrm{a}$ & $6.4650 \mathrm{a}$ & $8.0000 \mathrm{a}$ & $8.6438 \mathrm{a}$ & $9.8638 \mathrm{a}$ & $10.4000 \mathrm{a}$ & $10.8613 \mathrm{a}$ & $10.9450 \mathrm{a}$ \\
\hline $\mathrm{S} 3-\mathrm{H}_{50} \quad \mathrm{~V}_{50}$ & $1.8725 \mathrm{ab}$ & $2.7313 \mathrm{a}$ & $3.3700 \mathrm{a}$ & $5.5663 \mathrm{a}$ & $5.9988 \mathrm{a}$ & $6.8500 \mathrm{a}$ & $8.0987 \mathrm{a}$ & $9.6238 \mathrm{a}$ & $10.5188 \mathrm{a}$ & $10.3538 \mathrm{a}$ & $12.2663 \mathrm{a}$ & $12.5875 \mathrm{a}$ \\
\hline $\mathrm{S} 4-\mathrm{H}_{75} \quad \mathrm{~V}_{25}$ & $1.5813 \mathrm{ab}$ & $2.1425 \mathrm{a}$ & $3.0800 \mathrm{a}$ & $5.5300 \mathrm{a}$ & $5.8263 \mathrm{a}$ & $6.5900 \mathrm{a}$ & $7.6938 \mathrm{a}$ & $9.0700 \mathrm{a}$ & $10.2138 \mathrm{a}$ & $10.4313 \mathrm{a}$ & $11.4150 \mathrm{a}$ & $11.8863 \mathrm{a}$ \\
\hline $\mathrm{S} 5-\mathrm{H}_{100} \quad \mathrm{~V}_{0}$ & $1.5075 \mathrm{~b}$ & $2.1650 \mathrm{a}$ & $3.0663 \mathrm{a}$ & $5.0113 \mathrm{a}$ & $5.5413 \mathrm{a}$ & $6.2525 \mathrm{a}$ & $8.1250 \mathrm{a}$ & $9.1737 \mathrm{a}$ & $9.6513 \mathrm{a}$ & $10.4188 \mathrm{a}$ & $11.3750 \mathrm{a}$ & $12.4158 \mathrm{a}$ \\
\hline Teste F & $2.9372 *$ & $2.0787 \mathrm{NS}$ & $0.8336 \mathrm{NS}$ & $0.6812 \mathrm{NS}$ & $0.6133 \mathrm{NS}$ & $0.3321 \mathrm{NS}$ & $0.2058 \mathrm{NS}$ & $0.5134 \mathrm{NS}$ & $0.4173 \mathrm{NS}$ & $0.9504 \mathrm{NS}$ & $1.0174 \mathrm{NS}$ & $1.8756 \mathrm{NS}$ \\
\hline DMS (5\%) & 1.0870 & 1.1596 & 1.3683 & 1.4431 & 1.4952 & 1.6501 & 1.7578 & 2.0120 & 2.3171 & 2.0056 & 2.2065 & 2.1776 \\
\hline Interação E x S & $0.9081 \mathrm{NS}$ & $0.6310 \mathrm{NS}$ & $0.3224 \mathrm{NS}$ & $0.1533 \mathrm{NS}$ & $0.2427 \mathrm{NS}$ & $0.0894 \mathrm{NS}$ & $0.2842 \mathrm{NS}$ & $0.5457 \mathrm{NS}$ & $0.4891 \mathrm{NS}$ & $0.3479 \mathrm{NS}$ & $0.7524 \mathrm{NS}$ & $0.8308 \mathrm{NS}$ \\
\hline C.V. & $39.08 \%$ & $32.14 \%$ & $29.07 \%$ & $18.56 \%$ & $17.83 \%$ & $17.31 \%$ & $15.28 \%$ & $15.17 \%$ & $16.00 \%$ & $13.13 \%$ & $13.36 \%$ & $12.72 \%$ \\
\hline
\end{tabular}

Médias seguidas da mesma letra não diferem entre si, pelo teste de Tukey, a 5\% de probabilidade.

$\mathrm{NS}=$ não significativo 
TABELA 2 - Diâmetros de caules de tangerineira-Cleópatra e de limoeiro-Cravo cultivados em diferentes substratos e avaliados aos $104 ; 118$ e 132 dias após a semeadura (DAS).

\begin{tabular}{|c|c|c|c|}
\hline & $104 \mathrm{DAS}$ & 118 DAS & $132 \mathrm{DAS}$ \\
\hline ESPÉCIES & Diâmetro de Caules (m m) & Diâmetro de Caules (mm) & Diâmetro de Caules (mm) \\
\hline Tangerina-Cleópatra & $1,7595 \mathrm{~b}$ & $1,8990 \mathrm{~b}$ & $2,2100 \mathrm{a}$ \\
\hline Limão-Cravo & $1,9015 \mathrm{a}$ & $1,9860 \mathrm{a}$ & $2,2240 \mathrm{a}$ \\
\hline Teste F & $11,7500 * *$ & $5,41 *$ & $0,0457 \mathrm{NS}$ \\
\hline $\mathrm{DMS}(5 \%)$ & 0,0846 & 0,0764 & 0,1338 \\
\hline \multicolumn{4}{|l|}{ SUBSTRA TOS } \\
\hline $\mathrm{S} 1-\mathrm{H}_{\mathrm{O}} \mathrm{V}_{100}$ & $1,8500 \mathrm{a}$ & $1,9000 \mathrm{a}$ & 2,1138 a \\
\hline $\mathrm{S} 2-\mathrm{H}_{25} \mathrm{~V}_{75}$ & $1,8338 \mathrm{a}$ & $1,9263 \mathrm{a}$ & 2,1975 a \\
\hline $\mathrm{S} 3-\mathrm{H}_{50} \mathrm{~V}_{50}$ & $1,7875 \mathrm{a}$ & 1,9388 a & $2,2800 \mathrm{a}$ \\
\hline $\mathrm{S} 4-\mathrm{H}_{75} \mathrm{~V}_{25}$ & $1,8538 \mathrm{a}$ & $1,9600 \mathrm{a}$ & 2,1938 a \\
\hline $\mathrm{S} 5-\mathrm{H}_{100} \mathrm{~V}_{\mathrm{O}}$ & $1,8225 \mathrm{a}$ & $1,9875 \mathrm{a}$ & $2,3000 \mathrm{a}$ \\
\hline Teste F & $0,36 \mathrm{NS}$ & $0,63 \mathrm{NS}$ & $1,05 \mathrm{NS}$ \\
\hline $\mathrm{DMS}(5 \%)$ & 0,1899 & 0,1714 & 0,3002 \\
\hline Interação Espécies x Substratos & $0,32 \mathrm{NS}$ & $1,51 \mathrm{NS}$ & $0,21 \mathrm{NS}$ \\
\hline $\mathrm{C} \mathrm{V}$ & 7,16 & 6,09 & 9,34 \\
\hline
\end{tabular}

Médias seguidas da mesma letra não diferem entre si, pelo teste de Tukey, a 5\% de probabilidade.

NS = não significativo

$* \quad=$ significativo a $5 \%$

$* *=$ significativo a $1 \%$

TABELA 3 - Massas fresca e seca de raízes e de partes aéreas (g/planta) de tangerineira-Cleópatra e de limoeiro-Cravo cultivados em diferentes substratos.

\section{E S P É C I E S}

M A S S A F R E S C A R A ÍZES $(\mathrm{g} / \mathrm{pl} \mathbf{l})$

\section{A S S A S E C A \\ R A ÍZ E S ( g/p l)}

M A S S A F R E S C A P.A É R E A ( g/pl)
M A S S A SECA P. A É R E A $(\mathbf{g} / \mathbf{p l})$

\begin{tabular}{|c|c|c|c|c|c|}
\hline \multicolumn{2}{|c|}{ T ang.-C leópatra } & 0,7532 a & $0,1697 \mathrm{a}$ & $1,1261 \mathrm{a}$ & 0,3736 a \\
\hline \multicolumn{2}{|c|}{ Limoeiro-Cravo } & $0,6464 \quad b$ & $0,1581 \mathrm{a}$ & $1,1579 \mathrm{a}$ & 0,3519 a \\
\hline \multicolumn{2}{|c|}{ Teste F } & $4,4531 *$ & $1,0781 \mathrm{~N} \mathrm{~S}$ & $0,1506 \mathrm{~N} \mathrm{~S}$ & $0,8937 \mathrm{~N} \mathrm{~S}$ \\
\hline \multicolumn{2}{|c|}{ D M S $(5 \%)$} & 0,1035 & 0,0228 & 0,1675 & 0,0470 \\
\hline \multicolumn{6}{|c|}{ SUBSTRA TOS } \\
\hline $\mathbf{H}$ & $\mathbf{V}$ & & & & \\
\hline 0 & 100 & 0,6413 a & $0,1676 \mathrm{a}$ & $0,9254 \quad b$ & 0,3080 \\
\hline 25 & 75 & 0,6979 a & 0,1543 a & $1,0159 \mathrm{ab}$ & 0,3243 ab \\
\hline 50 & 50 & 0,7733 a & 0,1911 a & $1,3369 \mathrm{a}$ & $0,4171 \mathrm{a}$ \\
\hline 75 & 25 & 0,6968 a & 0,1575 a & 1,1839 ab & 0,3879 ab \\
\hline 100 & 0 & $0,6900 \mathrm{a}$ & 0,1488 a & $1,2478 \mathrm{ab}$ & $0,3764 \mathrm{ab}$ \\
\hline \multicolumn{2}{|c|}{ Teste F } & $0,6968 \mathrm{~N} \mathrm{~S}$ & $1,7926 \mathrm{~N} \mathrm{~S}$ & $3,3878 *$ & $3,1185 *$ \\
\hline \multicolumn{2}{|c|}{ D M S $(5 \%)$} & 0,2321 & 0,0512 & 0,3756 & 0,1055 \\
\hline \multicolumn{2}{|c|}{ Interação Ex S } & $1,1900 \mathrm{~N} \mathrm{~S}$ & $0,9683 \mathrm{~N} \mathrm{~S}$ & $0,4740 \mathrm{~N} \mathrm{~S}$ & $0,8410 \mathrm{~N} \mathrm{~S}$ \\
\hline \multicolumn{2}{|c|}{$\mathrm{C} \mathrm{V}(\%)$} & 22,88 & 21,56 & 22,69 & 20,05 \\
\hline
\end{tabular}

Médias seguidas da mesma letra não diferem entre si, pelo teste de Tukey, a 5\% de probabilidade.

$\mathrm{NS}=$ não significativo

* $=$ significativo a $5 \%$

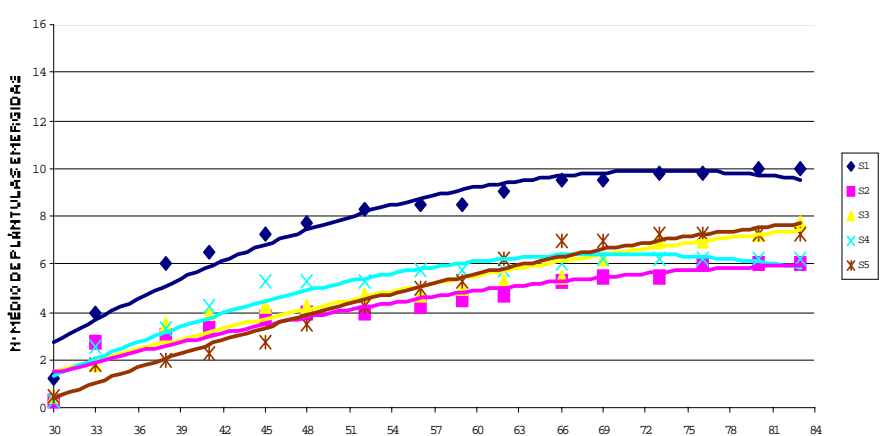

DAS

FIGURA 1 - Número médio de plântulas emergidas de tangerineira-Cleópatra $(\mathrm{CL})$ nos substratos $\mathrm{S} 1=$ $\left(\mathrm{H}_{0} \mathrm{~V}_{100}\right), \mathrm{S} 2=\left(\mathrm{H}_{25} \mathrm{~V}_{75}\right), \mathrm{S} 3=\left(\mathrm{H}_{50} \mathrm{~V}_{50}\right), \mathrm{S} 4=\left(\mathrm{H}_{75}\right.$ $\left.\mathrm{V}_{25}\right)$ e $\mathrm{S} 5=\left(\mathrm{H}_{100} \mathrm{~V}_{0}\right)$, em função dos dias após a semeadura (DAS).

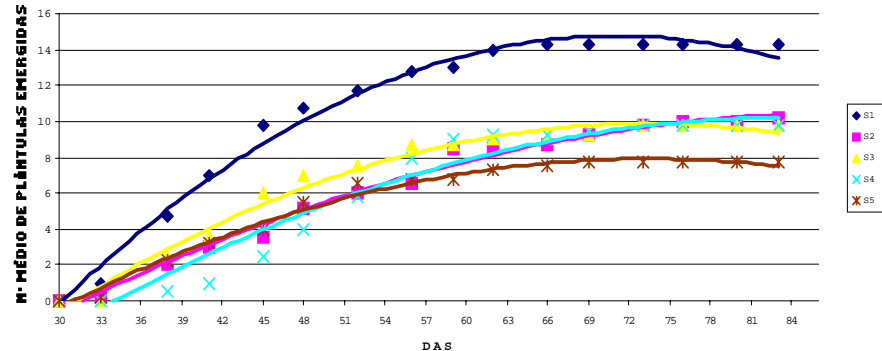

FIGURA 2 - Número médio de plântulas emergidas de limoeiroCravo (CR) nos substratos $\mathrm{S} 1=\left(\mathrm{H}_{0} \mathrm{~V}_{100}\right), \mathrm{S} 2=\left(\mathrm{H}_{25}\right.$ $\left.\mathrm{V}_{75}\right), \mathrm{S} 3=\left(\mathrm{H}_{50} \mathrm{~V}_{50}\right), \mathrm{S} 4=\left(\mathrm{H}_{75} \mathrm{~V}_{25}\right)$ e $\mathrm{S} 5=\left(\mathrm{H}_{100} \mathrm{~V}_{0}\right), \mathrm{em}$ função dos dias após a semeadura (DAS). 


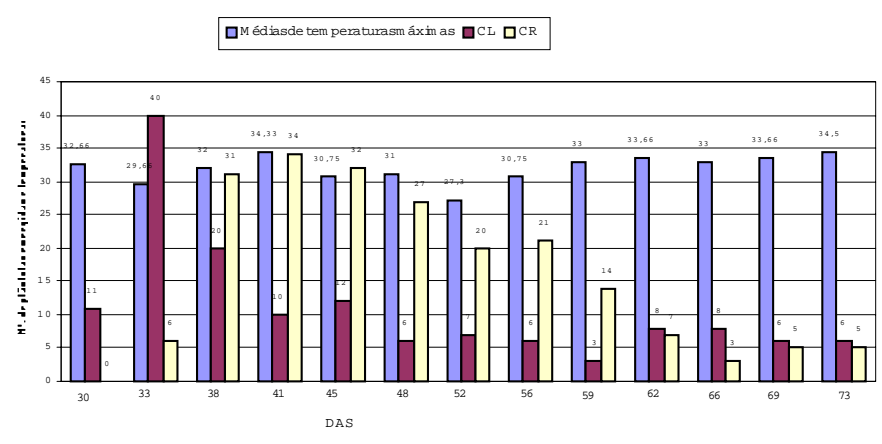

FIGURA 3 - Germinação de sementes de tangerineira-Cleópatra (CL) e de limoeiro-Cravo (CR) e temperaturas máximas médias nos diferentes períodos de avaliação.

entes em unidades móveis permitem padronização por lotes.

Quanto à contribuição nutricional do húmus pela sua composição química, esta não ficou evidente devido à eficiência do adubo encapsulado de liberação gradual que, provavelmente, supriu as necessidades das plantas em todos os tratamentos. Como neste estudo se trabalhou com a dosagem mínima recomendada (3 $\mathrm{kg}$ de $19-06-10 / \mathrm{m}^{3}$ de substrato), sugerem-se mais pesquisas quanto à dosagem, pois pode ocorrer de se necessitar de quantidades diferentes desta para conseguir resultados melhores.

\section{CONCLUSÕES}

Pela a interpretação dos resultados e análise dos dados neste estudo, conclui-se o seguinte:

1. a. Para massas fresca e seca de raiz, $50 \%$ de húmus e $50 \%$ de vermiculita destacou-se dos demais substratos, embora não diferisse estatisticamente dos outros tratamentos.

b. Para a parte aérea (massas fresca e seca), o substrato constituído de $100 \%$ de vermiculita foi igual aos demais, exceto a $50 \%$ de húmus e $50 \%$ de vermiculita, ao qual se mostrou inferior.

2. Com relação à precocidade, obtiveram-se plantas aptas ao transplantio (10 cm de altura) de tangerineira-Cleópatra e de limoeiro-Cravo aos 111 DAS nas condições em que foi desenvolvido este trabalho.

3. Quanto ao diâmetro do caule, aos 104 e 118 DAS, as plantas de limoeiro-Cravo mostraram-se superiores às de tangerineiraCleópatra (características das espécies), porém, o mesmo não ocorreu aos 132 DAS.

\section{REFERÊNCIAS BIBLIOGRÁFICAS}

CARLOS, E.F.; STUCHI, E.S.; DONADIO, L.C. Porta-enxertos para a citricultura paulista. Jaboticabal: FUNEP, 1997. 47p. (Boletim Citrícola, 1).

CARVALHO, S.A. Manejo da adubação nitrogenada na produção de porta-enxertos cítricos em bandejas. 1994. $74 \mathrm{f}$. Tese (Doutorado em Agronomia) - Escola Superior de Agricultura de Lavras, Lavras, 1994.

DAVIES, F.S.; ALBRIGO, L.G. Cítrus. 2. (Ed) . Wellingford: Crop Production Science in Horticulture. 2. ed. 1994. p. 56-57.

ESCOBAR, M.R.; GONÇALVES, J.S.; CARDOSO, J.L. Diferenças e similaridades entre os segmentos do complexo citrícola paulista. Agricultura em São Paulo, São Paulo, v. 46, t. 1, p. 59$88,1999$.

FUNDECITRUS. Viveiros. Araraquara. Disponível em <http:// www.fundecitrus.com.br>. Acesso em: 24-01-2001.

GONÇALVES, J.L.M.; POGGIANI, F. Substratos para produção de mudas florestais. In: CONGRESSO LATINO-AMERICANO DECIÊNCIA DO SOLO, 1996, Águas de Lindóia. Resumos: 1996.

JOAQUIM, D. Avaliação de três substratos para semeadura de limoeiro-Cravo (Citrus limonia, Osbeck), laranjeira-Caipira (Citrus sinensis L. Osbeck) e tangerineira-Cleópatra (Citrus reshni, Hort. Ex Tanaka) em bandejas. 1991. 133 f. Dissertação (Mestrado em Produção Vegetal) - Faculdade de Ciências Agrárias e Veterinárias, Universidade Estadual Paulista, Jaboticabal, 1991.

LIRA, L.M. Efeito de substratos e do superfosfato simples no limoeiro (Citrus limonia Osbeck cv cravo) em bandejas. 1990. 86 f. Dissertação (Mestrado em Agronomia) - Escola Superior de Agricultura de Lavras, Lavras, 1990.

NOGUEIRA, D.J.P. O clima na citricultura. Informe Agropecuário, Belo Horizonte, v. 52, n. 5, p. 3-13, 1979.

RADHAMANI, J.; MALIK, S.K.; CHADEL, K.P.S. Seedcoat characteristics in relation to the physiology of seed germanation in Citrus and its allied genus. Seed Science and Technology, Zürich n. 19, p. 611-621, 1991.

SEMPIONATO, O.R.; STUCHI, E.S.; DONADIO, L.C. Viveiro de citros. Jaboticabal. FUNEP, 1997. 37p. (Boletim Citrícola, 2). 